\title{
A visit to St Petersburg*: an experience of psychiatry in Russia
}

\author{
Ian P. Collins
}

Welcome To Reality' announces the bright orange graffito, in English, on the perimeter wall of The City Psychiatric Hospital Number 3. A superfluous arrow points to the gate house. This is a large general psychiatric hospital of 2150 beds serving a population of 1.7 million people and also providing my first experience of Russian psychiatry. The buildings, some wooden, date from 1870 onwards and are set in a large area of mature woodland enclosed by a high wall in the northern suburbs of the city.

Several features are immediately remarkable; the new Russian mental health legislation of 1993 is displayed near the entrance in a structure resembling a busshelter, each ward has its own garden area surrounded by a tall wire fence and seemingly guarded by one of a number of totem-like statues hewn from logs by patients. Nurses and doctors are conspicuous by their white coats.

\section{Wards}

I visited a variety of wards in several institutions; all were locked. Each ward may accommodate up to 100 patients of one sex and a wide variety of diagnoses in clean though basic and cramped conditions with minimal privacy. The living space of wards varies in quality from the homely, with pictures, flowers, easy chairs, icons and an area set aside for Orthodox church services, to the frankly stark with no decorations and overspill beds in place of easy chairs. There are bars on windows, no curtains around beds and no doors on the bedrooms, each of which contain up to 20 beds. New admissions and

-Previously known as Leningrad. the most disturbed patients are confined to an observation area. It seems that these features are common in most ex-Soviet psychiatric hospitals regardless of staff:patient ratios and reflect the long tradition of paternalism exercised by hospital authorities and, of course, the State. Some of the medical and nursing staff seemed preoccupied by the fear that unobserved patients might harm themselves and were not convinced that a

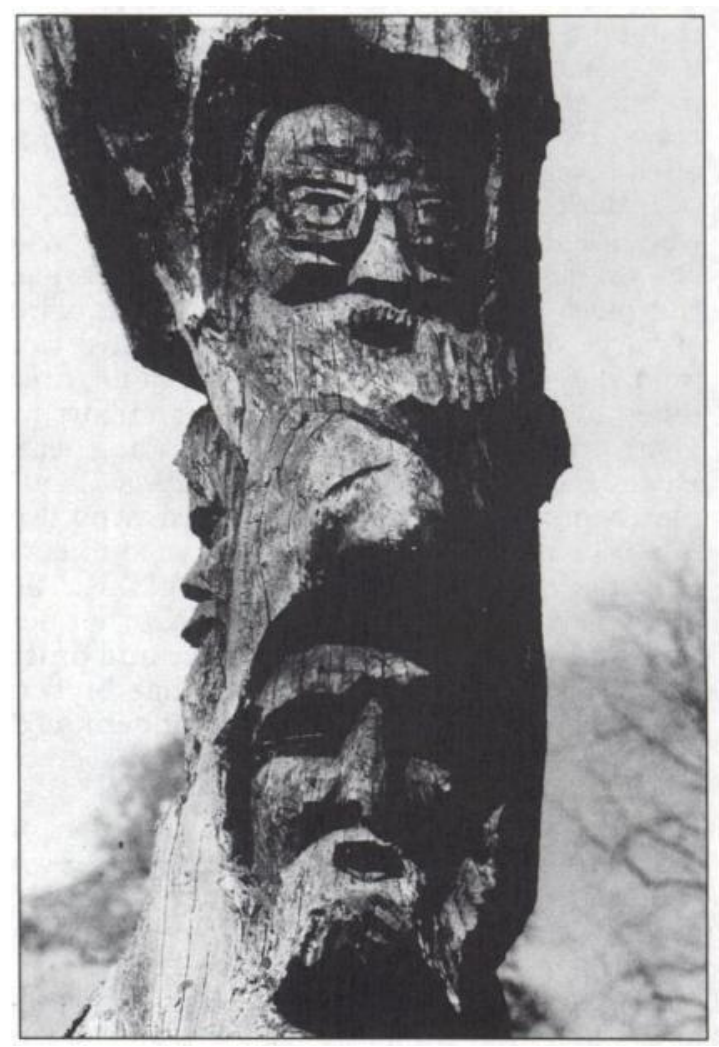

A statue hewn from logs by patients at The Clty Psychiatric Hospital Number 3, St Petersburg 
lack of privacy could be counter-therapeutic; they were astonished to learn that acutely ill patients are nursed in open wards in the United Kingdom. The degree of caution exercised by medical staff is illustrated by the requirement for decisions regarding parole to be signed by two doctors and for the additional signature and seal of the physician superintendent at the time of discharge.

\section{Stafiing}

The Number 3 Hospital has a permanent staff of 100 psychiatrists and 60 other full-time specialists including several physicians, neurologists, surgeons ${ }^{* *}$ and therapists***. The abundance of non-psychiatric medical staff is one consequence of the strong materialist leanings of Soviet psychiatry. Many hospitals in the former Soviet Union suffer from a shortage of trained and auxilliary nursing staff; in the Number 6 Hospital (adjacent to the Alexander Nevskd monastery) a typical busy ward of 100 patients was being run by five nurses and three doctors. It is difficult to fill vacant nursing posts as this is an unpopular occupation with little prestige due to its low rate of pay****, poor career prospects and subservient relationship to the medical profession. Several doctors expressed incredulity when informed of the therapeutic role of psychiatric nurses in the United Kingdom. Nurses undergo a three year general training, there being no specific programme for psychiatry. A consequence of the minimal responsibility given to nurses is that medical staff spend much of their time fulfilling the strict regulations regarding frequent entries into what are effectively combined medical and nursing notes.

\section{The dispensary system}

The dispensary system is central to Russian psychiatry and has its origins in the 19th century idea that illness is a product of the interaction between an individual and their physical and social environment over a period

" In this context, a surgically trained doctor whose full time role is to provide surgical opinions and undertake basic investigations within the institution. A patient requiring surgery will be referred to a surgeon in a general hospital.

**A graduate doctor with no specialist training. ***40.000 Roubles or $\$ 12$ per month in May 1994. of time. A 'psychoneurological dispensary' provides comprehensive out-patient psychiatric services tailored to the needs of a defined population of 200,000 to 400,000 people. There is a particular emphasis on long-term rehabilitation and follow-up. I visited a dispensary which has sectorised out-patient services, an alcohol and drug dependency treatment centre and a particularly impressive day hospital. The day hospital has a full-time staff of three doctors, ten trained nurses, three auxiliaries, a clinical psychologist and a total of 13 speech, occupational and physiotherapists for a list of 100 patients, most of whom are referred from out-patient services. There are also 15 'night hospital' beds for short-term use of patients with acute social problems. Seventy or so patients attend on a given day to recetve a wide variety of treatments including intravenous infusions, massage, physiotherapy, relaxation sessions, occupational therapy and individual or group psychotherapy. I was struck by the absence of patients engaged in smoking or watching television!

\section{Treatments}

There is a particular emphasis on physical treatments and this partially reflects the legacy of influential 19th century physiologists such as Pavlov and the ideologically motivated materialism of Soviet psychiatry with its rejection of 'Western' dualistic thinking. In-patients will be assessed by a number of medical specialists and the majority will undergo electroencephalographic examination. An academic unit was investigating the use of haemodialysis 'detoxification' in the treatment of acute schizophrenia.

In-patient treatment of major depressive illness in a physically healthy subject is likely to begin with intravenous infusion of a tricyclic antidepressant at doses of up to $400 \mathrm{mg}$ per $24 \mathrm{~h}$ with the patient being kept in bed to facilitate this. There is an expectation of improvement in sleep, concentration and energy within the first week of treatment and the fear that 'low' or gradually increasing doses of tricyclics induce treatment resistance. It is also believed that treatment resistance in psychotic illnesses may be overcome by using sulphazin injections to produce a therapeutic pyrexia of about $40^{\circ} \mathrm{C}$ for two days, or as a last resort by the use of insulin coma though such 
treatments are rarely used and need the consent of the patient and approval of a large case conference.

Patients suffering from a range of 'neurotic' disorders are likely to be given traditional herb extracts and 'tonic' infusions of glucose, vitamins and glycerophosphates in addition to a structured programme of physiotherapy. relaxation. occupational therapy and individual or group psychotherapy.

Electroconvulsive therapy (ECT) is sparingly used in Russia. The Number 3 Hospital, despite its size, uses only one or two ECT treatments per day and this seems to reflect the fear that the procedure may cause irreversible brain damage. The indications given for its use would be familiar to most UK trained psychiatrists although its early and frequent (two to three times per day) use in 'febrile schizophrenia' (neuroleptic malignant syndrome), and its left unilateral administration for treatment resistant auditory hallucinations might be thought of as controversial. ECT is usually given in an unmodified form because of the belief that the administration of a general anaesthetic reduces the efficacy of a treatment and increases seizure threshold to a degree that necessitates the use of significantly higher electrical charges to produce convulsions. It would seem that any advantage gained by this technique is lost in the gross variability of the electrical charge delivered by constant voltage ECT apparatus, considered obsolete in the United Kingdom and the only type I saw during my visit. Patients are assessed by a physician, surgeon and neurologist prior to ECT and will be excluded from treatment if they are physically unfit, elderly or unwilling to give consent. The psychiatrists I spoke with were surprised to learn that ECT is seen as the treatment of choice for major depression in the elderly in the UK.

Psychotherapies are widely used although they are usually short-term, directive and rational with a view to producing environmental as well as intrapsychic changes. 'In depth' therapies have tended to be seen as dualist, bourgeois and therefore politically incorrect, although a greater impediment to their widespread use may be a cultural one-there is simply a strong tradition of keeping oneself to oneself which is reinforced by memories of times when the mere suspicion that one held 'incorrect' ideas could have serious consequences. It seems that Russians are suspicious of doctors in general and psychiatrists in particular; many would-be patients turn instead to traditional remedies based on the use of hot baths, massage, herbs and vodka.

\section{Impressions}

My visit left me with a set of powerful impressions; the physician superintendent who had to decide whether to pay the hospital fuel bill or staff salaries, the wooden Orthodox hospital chapel holding services again some 50 years after the choir were executed during Stalin's purges, the smell of overcrowding and institutionalisation, the dedication of poorly paid and overworked staff, the grindings of bureaucracy and the pervasive though slowly yielding resistance to questioning accepted practices.

\section{Acknowiedgements}

I wish to record my thanks to the patients and staff of Psychiatric Hospitals Number 3 and 6 for their warm welcome and for answering my many questions. I am particularly grateful to Drs Marina and Andrei Popov for their kindness and hospitality and to Dr Peter and Mrs J. Scott for their financial support.

Ian P. Collins, Senior Registrar, Lucille van Geest Centre, Peterborough District Hospital, Peterborough PE3 6DA 